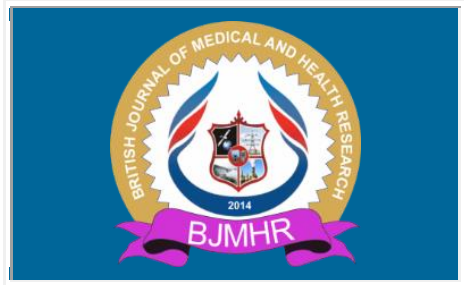

\title{
BJMHR
}

British Journal of Medical and Health Research

Journal home page: www.bjmhr.com

\section{Societal Usage Of Antibiotics In The Syrian Coastal Region During 2021}

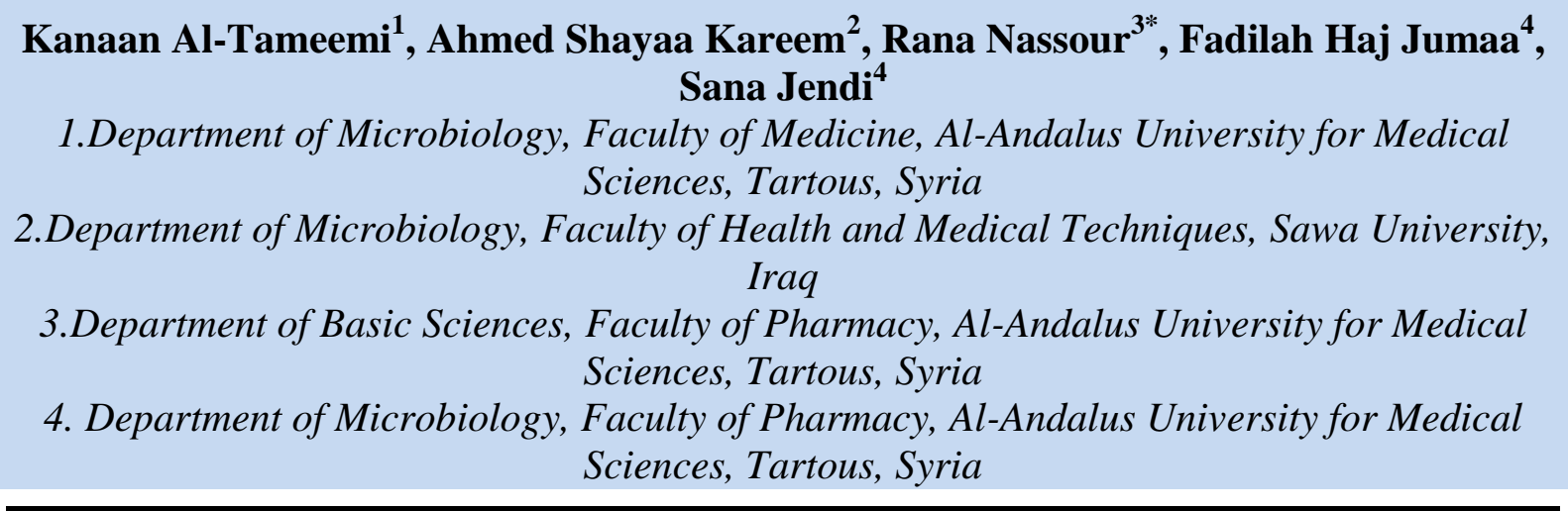

\section{ABSTRACT}

This study is based on an electronic questionnaire about the use of antibiotics. It investigates the knowledge about antibiotics and their resistance among the Syrian coastal people. 639 individuals responded to the questionnaire. The results show that there is fairly good information about those drugs. Yet, there is much to be done to spread the awareness in the whole community, especially with regards to enact laws that prohibit antibiotics purchase without a prescription. Doctors on the other hand, should give antibiotics only on necessity. People also have to be well educated about antibiotics resistance, which is an inevitable consequence to the misuse of those drugs.

Keywords: Antibiotics, Misuse, Resistance, Awareness, Infection. 


\section{INTRODUCTION}

The word "antibiotic" is formed from the prefix (anti-), meaning fighting, opposing or killing, and the Greek word (bios), meaning life, thus "life killing", The doctors prescribe antibiotics to kill the bacteria responsible for infections in the body ${ }^{1}$. Antibiotics are substances produced naturally in many microorganisms like bacteria or fungi ${ }^{2,3}$. Humans were highly exposed to infections prior to the discovery of antibiotics. Various diseases like tuberculosis were hardly treated or not at all. The world lived with the fear of major epidemics, and experienced high mortality rates over the years as a result of infections ${ }^{3}$.

As for antibiotic discovery, Paul Ehrlich discovered Salvarsan in 1909, the first antibiotic against the spirochete Treponema pallidum, which cause syphilis 3, 4, 5, 6, 7, 8, 9 . Ehrlich's concept of a "magic bullet" which selectively affects only pathogenic microbes was based on an observation that aniline and other synthetic dyes stain specific microbes but not others ${ }^{8}$, ${ }^{10}$.This discovery laid the foundations for the further development of antimicrobial agents. However, the milestone in the antibiotic development was the discovery of penicillin in 1928 by Alexander Flemming, who accidentally got it after noticing that growth of Staphylococcus aureus was inhibited in a contaminated medium with Penicillium notatum. The discovery of penicillin was first reported in 1929, and clinical studies were performed on humans in 1940 for the first time ${ }^{3,5,6,7,9,11,12}$. Penicillin discovery was deemed a contemporary miracle, as it could treat all Staphylococci and Streptococci infections. The relief following this discovery is completely understandable, considering that these two pathogens are responsible for a large number of known diseases ${ }^{3,13}$. Since then, doctors were able to broaden and advance their research. Over the years, dozens of antimicrobial agents were discovered, having several mechanisms of action ${ }^{3}$.

In the modern era, new semi synthetic derivatives have been developed, and new term "antimicrobials" appeared instead of "antibiotics". Antimicrobials indicates to natural, semisynthetic and synthetic substances capable of supressing the proliferation of microbes and resulting in their apoptosis ${ }^{3}$.

In general, some antibiotics "bactericidal" kill bacteria, while others "bacteriostatic" only inhibit their growth $1,2,6,14,15$. Most antibiotics have their effect via inhibiting cell wall synthesis, leaking through cell wall, supressing protein synthesis, damaging bacterial DNA and/or metabolism ${ }^{1,7}$.

Antibiotics are used against bacterial infections. Some of them are quite specialised and attack certain bacteria. Others, known as broad-spectrum antibiotics, affect a wide range of bacteria, including the beneficial ones ${ }^{7}$. 
Various ways are accepted in classifying antibiotics, but the most common classification is based on their structures, mode of action and spectrum of activity ${ }^{1,6}$. Others depend on the route of administration (topical, injectable or oral). Generally, antibiotics of the same structural class show similar form of effectively, toxicity and allergic-potential side effects ${ }^{1,6}$. To date, at least 4,000 antibiotics were isolated from cultures of microbes and over 30,000 were prepared semisynthetic. However, nearly 100 of these are used daily ${ }^{2}$. Over the past decade, the global antibiotic usage increased remarkably ${ }^{16}$.

In another context, although antibiotics saved lives and played an essential role in achieving significant advances in medicine and surgery ${ }^{17}$. However, unfortunately, people believed that antibiotics could cure anything, so they used them widely, repeatedly and unnecessarily. This extensive use of antibiotics led to the spread of resistant phenotypes and the emergence of multidrug-resistant pathogens ${ }^{17}$. Microorganism's ability to resist antimicrobial agents has surpassed our imagination. In some cases, formerly used antimicrobial agents are no longer effective ${ }^{5}$.

Consequently, after many decades of the discovery of antibiotics, bacterial infections become a threat once again. The antibiotic resistance can be attributed to the overuse and misuse of these drugs, along with the changes in the genetic material of the microorganism, mutations in one or some of the genes or with a new gene and the lack of new drug development ${ }^{2,12,17}$, 18

Nowadays, resistance of antibiotics is a global phenomenon, which concerns the World Health Organization (WHO) along with individual countries. In 2016, WHO reported that more than 700,000 people worldwide die every year because of drug-resistant diseases ${ }^{15}$. Hence, the period of 18 to 24 November was specified as the World Antimicrobial Awareness Week (WAAW). It is celebrated annually, and attempts to increase awareness of antibiotic and antimicrobial resistance problem and to encourage best practices among the patients and physicians to avoid further spread of drug-resistant pathogens. Besides, awareness-raising campaigns are made worldwide to reduce the over-consumption of antibiotics and antimicrobial agents, considering that many documented studies support, indubitably, that restricting the misuse of antibiotics decreases resistance ${ }^{2,19}$.

\section{MATERIALS AND METHODS}

A multi-question questionnaire, regarding the use of antibiotics in the Syrian costal region, was prepared electronically and sent via social media in June 2021. 639 people responded and answered the questions. The reliability of the questionnaire was measured using Cronbach Alpha (internal consistency) test. 


\section{RESULTS AND DISCUSSION}

639 people responded and answered the questionnaire, and the results were as the following: According to the first question, most of the subjects $(42.1 \%)$ occasionally get a prescription sometimes before taking the antibiotics, while $19.5 \%$ do not (Figure 1) and $70.5 \%$ of the latter consult the pharmacists to get their medication (Figure 2).

Do you always get a prescription before you start taking antibiotics?

620 answers

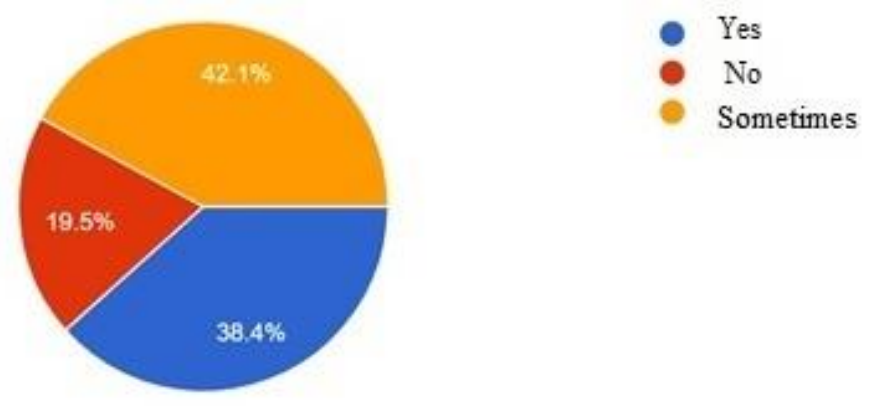

Figure 1: Question 1

If you use antibiotics without a prescription, what is your source for treatment?

579 answers

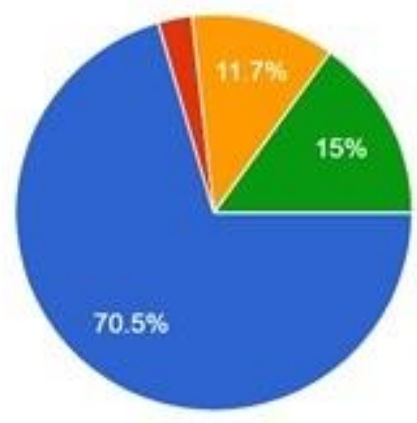

Pharmacies

Internet

Someone's advice

Remaining drug from a

previous treatment

Figure 2: Question 2

When taking antibiotics, $69.9 \%$ continue the course of the treatment after feeling better, whereas $30.1 \%$ stop after improving a little bit (Figure 3). Generally, $56.3 \%$ of the community have a previous knowledge about the risks of not completing the course of the treatment (Figure 4). In the case of not getting better immediately upon treatment, $68 \%$ of people consult a doctor and $28.6 \%$ continue taking the medicine until the end of the course of treatment (Figure 5). 
Do you stop taking your prescribed antibiotics after getting better, or do you continue your course of treatment?

618 answers

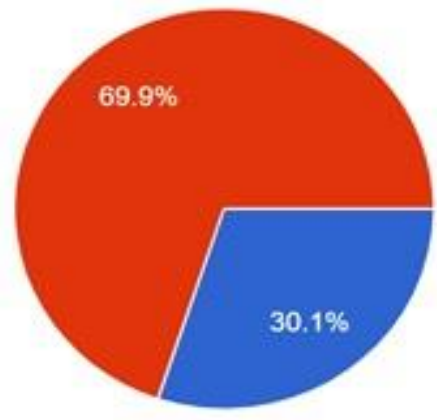

Stop after getting better

Continue the treatment

Figure 3: Question 3

Do you know the risks of not completing the antibiotic course?

620 answers

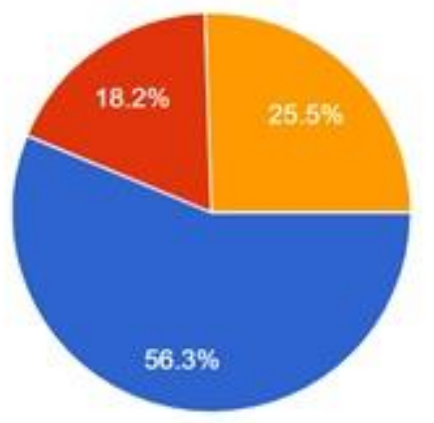

Y Yes

- No

A little

Figure 4: Question 4

What do you do if you do not get better after treatment? 616 answers

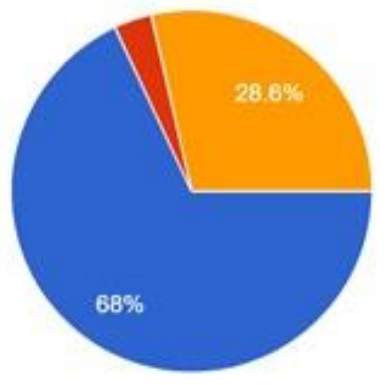

Consult a doctor

Change the antibiotic without a medical advice

Continue taking the medicine until the end of the treatment course

\section{Figure 5: Question 5}

As for question 6 "Do you keep the rest of antibiotics for the next time you get sick?", 44.6\% of people keep them always while $28.7 \%$ occasionally do (Figure 6). Besides, most of them $(50.7 \%)$ don't give the remaining medicine to family or friends as the result of the question 7 indicate (Figure 7). In addition, most of people (57.6\%) use the same antibiotics if they had the same symptoms again (Figure 8). 
Do you keep the rest of the antibiotics for the next time you get sick?

621 answers
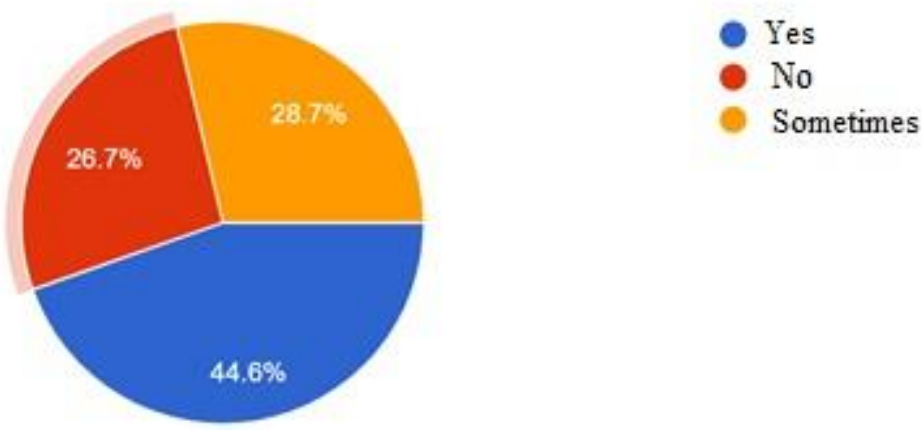

Figure 6: Question 6

Do you give remaining medicine to family or friends if they get sick?

621 answers
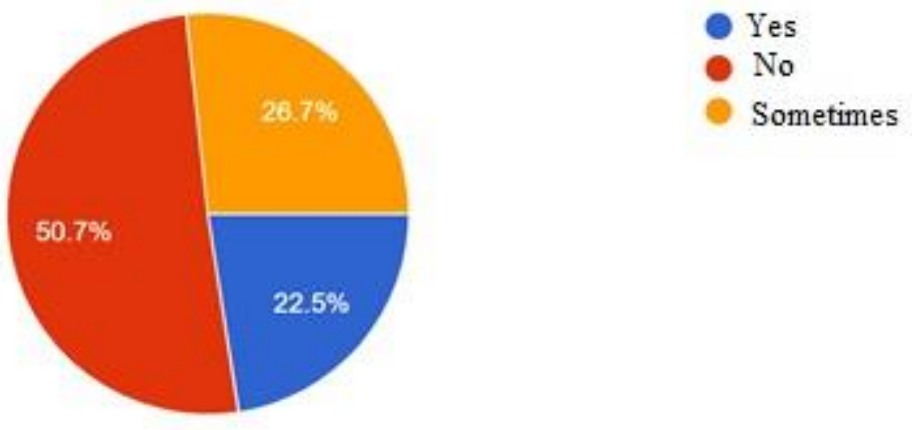

Figure 7: Question 7

If you improve after using certain antibiotics, would you buy the same antibiotics if you get sick again with the same symptoms?

622 answers

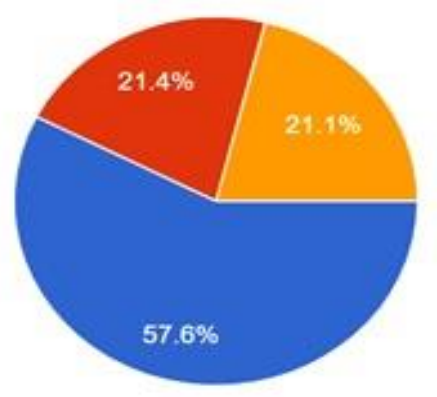

- Yes

- No

- Sometimes

\section{Figure 8: Question 8}

As for question 9 "In your opinion, what is the main reason for the phenomenon of indiscriminate use of antibiotics without a prescription?", most of the people involved in the questionnaire (72.6\%) think that the main reason is the lacking awareness about the risks (Figure 9). 
In your opinion, what is the main reason for the phenomenon of indiscriminate use of antibiotics without a prescription?

588 answers

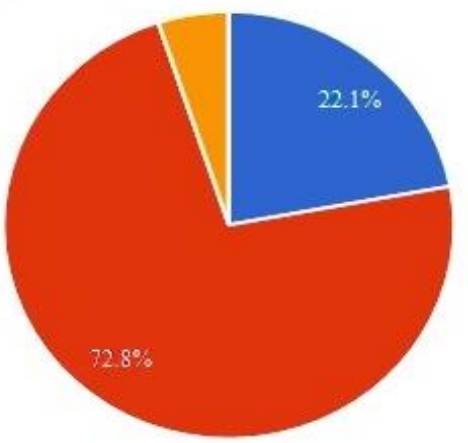

- Economic status

- Insufficient awareness about the risks in the community

- Lack of strict control over the random antibiotics dispensing

Figure 9: Question 9

$44.2 \%$ of the people who answered the questionnaire know that antibiotics are not useful in the cases of cold or flu (Figure 10), and 79.6\% do not use antibiotics when they have the first cold or flu symptoms (Figure 11).

Do you think that antibiotics are useful in cases of cold or flu?

620 answers
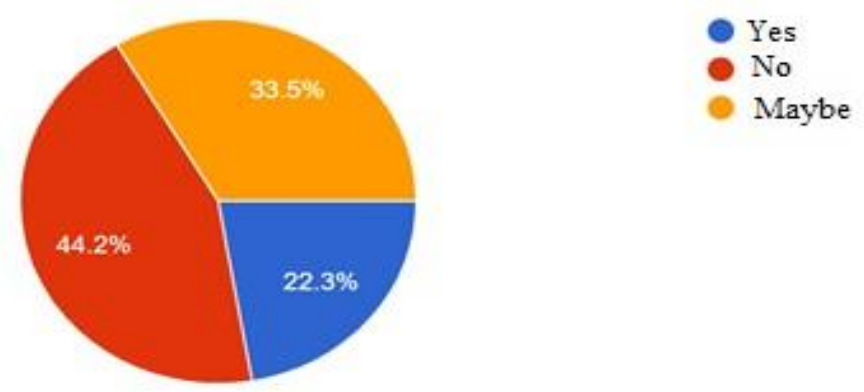

Figure 10: Question 10

Have you ever used antibiotics to prevent the disease when you start having cold or flu symptoms?

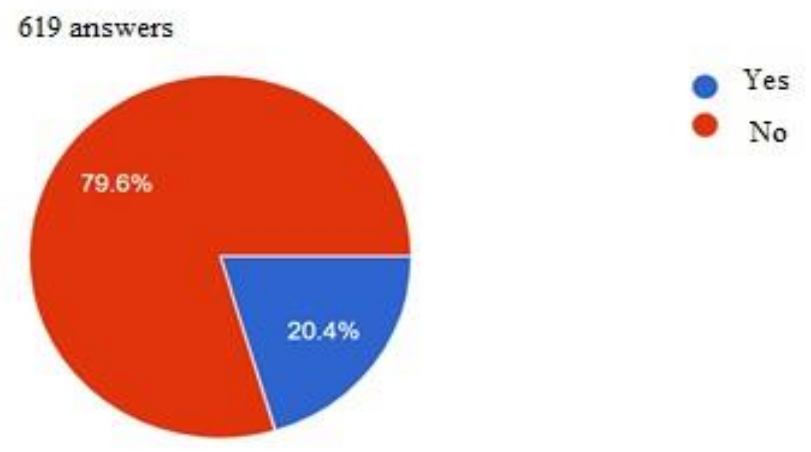

Figure 11: Question 11

According to our questionnaire, $72.8 \%$ do not consider antibiotics safe drugs (Figure 12), and 73.3\% think that they should be used only upon a medical advice (Figure 13). In fact, the majority of people $(75.3 \%)$ believe that the human body can usually overcome the mild infections on its own (Figure 14). 
Do you think antibiotics are safe drugs, and can be commonly used?

618 answers

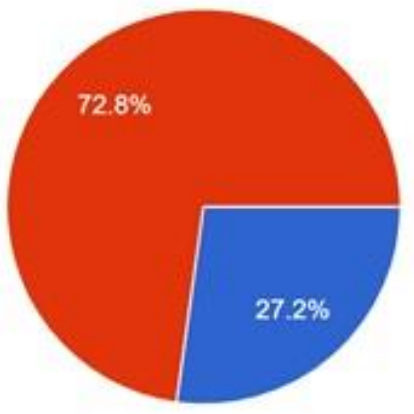

Yes

No

Figure 12: Question 12

Do you think antibiotics should be used only when prescribed by a doctor? 618 answers

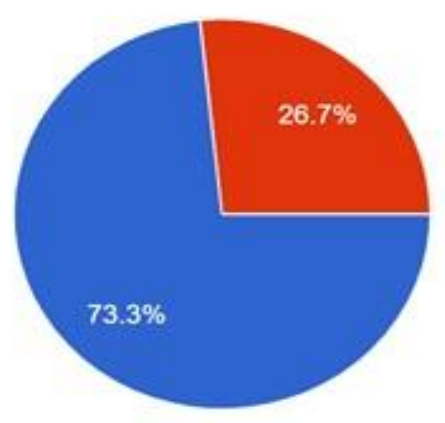

Yes
No

Figure 13: Question 13

Do you think that the body can usually fight mild infections without using antibiotics? 619 answers
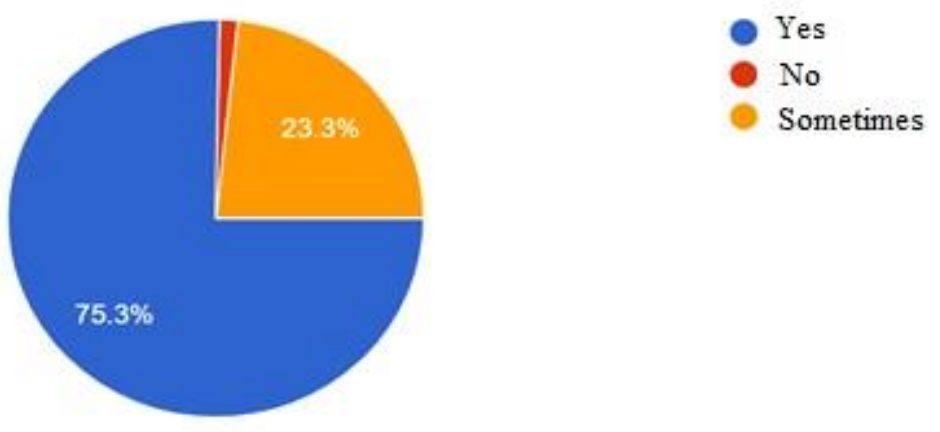

Figure 14: Question 14

With regards to question $15,55.5 \%$ believe that antibiotic sensitivity tests help determining the affectivity of a bacterial infection, while $41.2 \%$ have no idea about that (Figure 15). Despite that, $82.7 \%$ of people have never done an antibiotic sensitivity tests at all (Figure 16). 
Can antibiotic sensitivity tests (bacterial culture) help to determine whether a particular antibiotic is effective in treating a particular bacterial infection?

616 answers
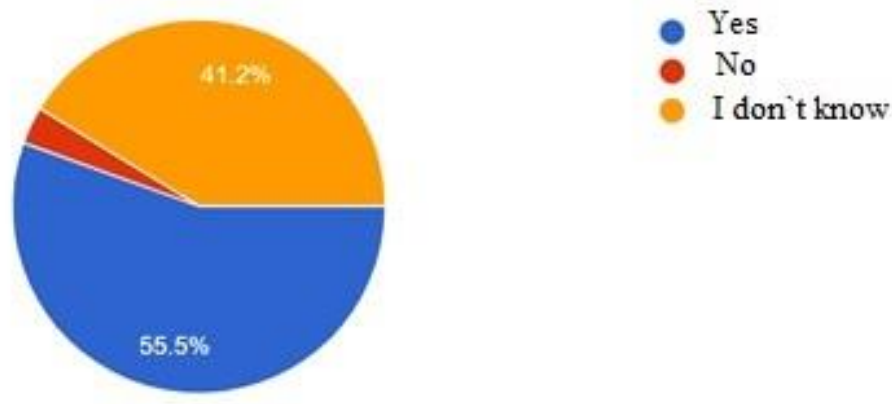

Figure 15: Question 15

Have you ever had a bacterial culture test to determine which antibiotic is right for you to use?

617 answers

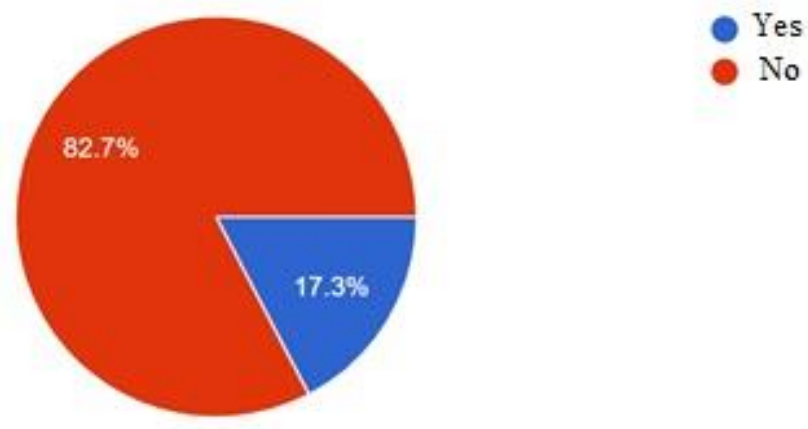

Figure 16: Question 16

Concerning question 17 of the questionnaire "In your opinion, is antibiotic resistance representing a problem in the world?" 616 answered and $50.2 \%$ believe that antibiotic resistance will represent a big problem and threaten humanity in the future. While $18 \%$ think that it is a minor problem, and $27.8 \%$ have no clue about that (Figure 17).

In your opinion, is antibiotic resistance representing a problem in the world?

616 answers

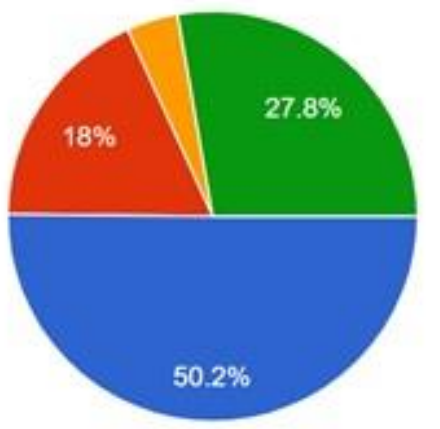

Yes, it is a big problem that may threaten humanity in the future

Yes, but it is not a big problem

No it's not a problem

I don $t$ know

Figure 17: Question 17 
According to the last question of the questionnaire, it seems that the picture is not clear in the community, since $44 \% \%$ suspect that they may have a role to play in reducing the antibiotic resistance and $43.1 \%$ believe that they have a role in it (Figure 18). Finally, the Cronbach Alpha for our questionnaire is 0.972 , which shows that the items within that scale (internally) are reliable.

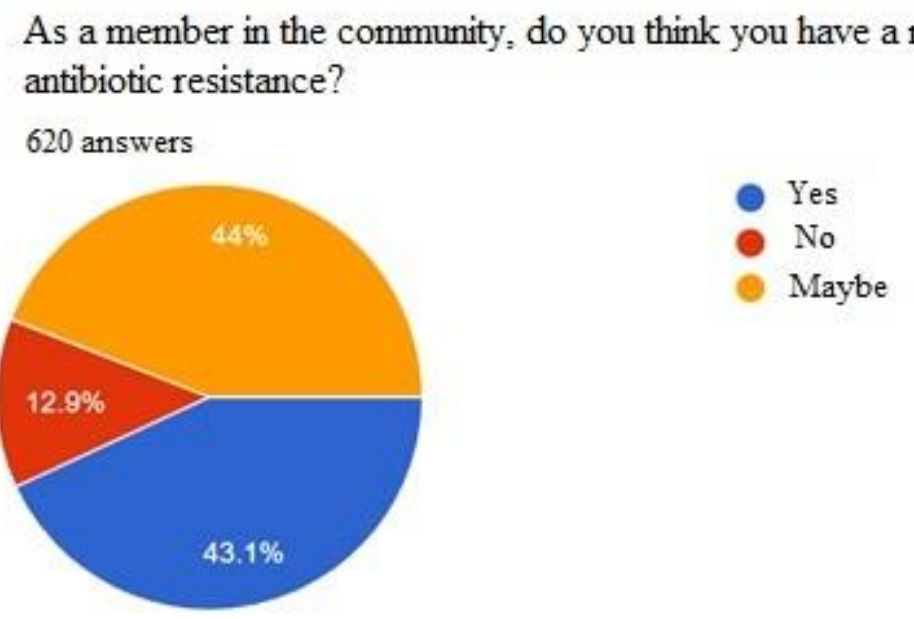

Figure 18: Question 18

Our questionnaire shows that our community lacks some awareness of using antibiotics, as many malpractices contribute to increasing the resistance of pathogens to medicines.

There are some positive points. For example, $68.9 \%$ of the people who responded to the questionnaire usually complete the course of treatment, $56.3 \%$ of them have prior knowledge of the risks of not completing it, $72.8 \%$ believe that antibiotics are not safe to be used very commonly and $75.3 \%$ think that the body can overcome mild infections without taking any medication.

On the other hand, we observe that some concepts should be corrected. For example, selfmedication and random purchasing of antibiotics form pharmacies. This indicates the importance of having legislation to prevent the purchase of antibiotics without a prescription. Actually, in many countries, especially in low- and middle-income ones, prescriptions are not controlled strictly enough, allowing resistance to develop more quickly ${ }^{7,20,21,22}$.

Besides, according to our study, $82.7 \%$ did not do a bacterial culture to identify the cause of infection and define the perfect antibiotic for treatment. This leads to poor and uncertain diagnosis; therefore, broad- spectrum antibiotics are prescribed here for the proper diagnosis 7, 23. Moreover, antibiotics are taken sometimes to treat the common cold or flu, which are viral diseases and antibiotics are completely useless against them, which in turn also causes an increase in antibiotic resistance ${ }^{7,24}$.

Antibiotic resistance occurs naturally to allow the microorganisms to survive and is an unavoidable consequence for even wise antibiotic usage, it is clear that the process is accelerated by overuse and misuse of antibiotics ${ }^{22,25}$. This facilitates the spread of 
spontaneous mutations which promote survival and shortens the time bacteria need to acquire resistance to new medications ${ }^{7,22,26}$. Furthermore, the FDA clarifies that skipping doses, saving and sharing antibiotics also contribute in the formation of bacterial resistance ${ }^{23,27}$.

It`s worth noting that antibiotics are increasingly used in livestock farming, in order to meet the growing demand of animal protein. Consequently, resistance in animals is formed, and simply transmitted to humans through animal-derived products ${ }^{7,28,29}$.

Several methods are involved in bacterial resistance to antibiotic, including:

1. Enzymatic inactivation of the antibiotic, since one of the cellular enzyme is altered to react with the antibiotic and make it ineffective on the microorganism (like the penicillinases, a group of $\beta$-lactamase hydrolysing enzymes, that cleave the $\beta$-lactam ring of the penicillin molecule and thus change its structure) $7,30,31,32,33,34,35,36,37$.

2. Reducing the antibiotic binding to the cell target sites through modifying these targets so they would not be recognized by the antibiotic (as in the case of $\beta$-lactams, erythromycin, lincomycin) ${ }^{7,30,33,34,35}$.

3. Minimizing the uptake of the antibiotics into the cell, especially in Gram-negative bacteria, which have an outer membrane works as an additional barrier inhibiting the penetration of many antibiotics. This membrane includes proteins "porins" that are correlated for the modulation of cellular permeability. This is similar to what happens with chloramphenicol $7,30,35,38,39,40$.

4. Activating the antibiotic efflux from the cell (e.g., tetracycline) $7,26,30,31,34,35,37$.

5. Overproduction of antibiotic target sites (like sulphonamides and trimethoprim) ${ }^{7,30}$ 41

6. Metabolic bypass of inhibited reaction (such as, sulphonamides and trimethoprim) ${ }^{7}$, 30,31

Antibiotic resistance affects every country because bacterial resistant strains can cross international borders and spread globally; easily and quickly ${ }^{7,23,42}$.

Finally, it is essential to use antibiotics only when they are really needed. Normally, specific antibiotics are better than broad-spectrum ones because they only affect certain bacterial types. This ensures that many antibiotics remain useful and effective for as long as possible ${ }^{7}$, 43 . Proper use of antibiotics by doctors and patients is vital so that they stay as the "guardianangel" of all patients against infections ${ }^{3,40,44}$.

\section{CONCLUSION}

Our questionnaire refers to a lack of knowledge concerning antibiotics in general. The answers indicates to an indiscriminate and over-consumption of those medications. Today, extensive efforts should be aimed at promoting education on the mechanism of antibiotics, 
antibiotic resistance and rational use of them among individuals and medical professionals, in order to slow down the antibiotic resistance process.

\section{ACKNOWLEDGEMENTS}

The authors thank Al-Andalus University for its support.

\section{REFERENCES}

1. Khan F. Antibiotics Classification and Visual Target Sites for Bacterial Inhibition. Advances in Pharmacology and Clinical Trials. 2018; 3 (3): 1-3.

2. Kourkouta L, Kotsiftopoulos C, Papageorgiou M, Iliadis C, Monios A. The rational use of antibiotics medicine. Journal of Healthcare Communications. 2017; 2(3): 1-4. DOI: $10.4172 / 2472-1654.100067$.

3. Kourkouta L, Tsaloglidou A, Koukourikos K, Iliadis C, Plati P, Dimitriadou A. History of Antibiotics. Sumerianz Journal of Medical and Healthcare. 2018; 1(2): 5154.

4. Bosch F, Rosich L. The contributions of Paul Ehrlich to pharmacology: A tribute on the occasion of the centenary of his Nobel Prize. Pharmacology. 2008; 82: 171-79. DOI: $10.1159 / 000149583$.

5. Saga T, Yamagu K. History of antimicrobial agents and resistant bacteria. JMAJ. 2009; 52(2): 103-108.

6. Etebu E, Arikekpar I. Antibiotics: Classification and mechanisms of action with emphasis on molecular perspectives. IJAMBR. 2016; 4: 90-101.

7. Factfile: Antibiotic resistance: A challenge for the $21^{\text {st }}$ century. Microbiology Society. $2017 ; 1-12$.

8. Nicolaou KC, Rigol S. A brief history of antibiotics and select advances in their synthesis. The Journal of Antibiotics. 2018; 71: 153-184.

9. Hutchings MI, Truman AW, Wilkinson B. Antibiotics: past, present and future. Current Opinion in Microbiology. 2019; 51: 72-80. DOI: 10.1016/j.mib.2019.10.008.

10. Aminov RI. A brief history of the antibiotic era: lessons learned and challenges for the future. Frontiers in Microbiology. 2010; 1: 134. DOI: 10.3389/fmicb.2010.00134.

11. Davies J, Davies D. Origins and evolution of antibiotic resistance. Microbiology and Molecular Biology Reviews. 2010; 74 (3): 417-433. DOI:10.1128/MMBR.00016-10.

12. Alduina R. Antibiotics and Environment. Antibiotics. 2020; 9: 202. DOI: 10.3390/antibiotics9040202

13. Cebeci A, Kırmusaoğlu S. Introductory Chapter: An Overview of the Genus Staphylococcus and Streptococcu. In: Kırmusaoğlu S (ed). Staphylococcus and 
Streptococcus. [document on the Internet. Published in March $11^{\text {th }}$ 2020]. DOI: 10.5772/intechopen.90798.

14. Calderon CB, Sabundayo BP. Antimicrobial classifications: Drugs for bugs. In: Schwalbe R, Steele-Moore L, Goodwin AC (ed). Antimicrobial susceptibility testing protocols. USA: CRC Press, Taylor and Frances group; 2007. p. 7-52.

15. Valavanidis A. and antimicrobial resistance. A new discovery of antibiotic teixobactin: treating infections without detectable bacterial resistance. Pharmakeftiki. 2017; 29 (I): 1-11.

16. Salm F, Schneider S, Schmücker K, Petruschke I, Kramer TS, Hanke R, et al. Antibiotic prescribing behavior among general practitioners - a questionnaire-based study in Germany. BMC Infectious Diseases. 2018; 18: 208. DOI: 10.1186/s12879018-3120-y.

17. Vent CL. The Antibiotic Resistance Crisis, Part 1: Causes and Threats. P\&T. 2015; 40 (4): $277-283$.

18. Bertrand X, Hocquet D. Antibiotic drug resistance: Causes and solutions. EJHP Practice. 2011; 17 (2): 58-59.

19. World Health Organization. World Antimicrobial Awareness Week. [Document on the Internet]. Available from: https://www.who.int/campaigns/world-antimicrobialawareness-week (accessed in July 15 ${ }^{\text {th }} 2021$ ).

20. Al-Akhali KM, Alzomar AK, Khan NA, Alavudeen SS. Misuse of antibiotics and awareness of antibiotic hazard among the public and medical professionals in Thamar Province, in Republic of Yemen. Pharmacie Globale (IJCP). 2013; 4 (1): 1-4.

21. Michael CA, Dominey-Howes D, Labbate M. The antimicrobial resistance crisis: causes, consequences, and management. Frontiers in Public Health. 2014; 2: 145. DOI: 10.3389/fpubh.2014.00145.

22. Deolalikar A, Desiraju K, Laxminarayan R, Pittet D, Tollman S, Wilson ME. The State of the world's antibiotics 2021. A global analysis of antimicrobial resistance and its drivers. The Center for Disease Dynamics, Economics \& Policy (CDDEP); 2021; $1-136$.

23. Shallcross LJ, Davies DSC. Antibiotic overuse: A key driver of antimicrobial resistance. British Journal of General Practice. 2014; 604-605. DOI: 10.3399/bjgp14X682561.

24. Surji KM. Antibiotics misuse and factors leading to its abuse in Kurdistan Region. Journal of Health, Medicine and Nursing. 2016; 24: 20-27. 
25. Ali J, Rafiq QA, Ratcliffe E. Antimicrobial resistance mechanisms and potential synthetic treatments. Future Sci. OA. 2018; 4(4): FSO290. DOI: 10.4155/fsoa-20170109.

26. Munita JM, Arias CA. Mechanisms of Antibiotic Resistance. Microbiol Spectr. 2016; 4(2): 1-37. DOI:10.1128/microbiolspec.VMBF-0016-2015.

27. FDA. Combating Antibiotic Resistance [document on the Internet]. [Updated 2019 October 10]. Available from: https://www.fda.gov/consumers/consumerupdates/combating-antibiotic-resistance (accessed in July $19^{\text {th }} 2021$ ).

28. Landers TF, Cohen B, Wittum TE, Larson EL. A review of antibiotic use in food animals: Perspective, policy, and potential. Public Health Reports. 2012; 27(1): 4-22.

29. Manyi-Loh C, Mamphweli S, Meyer E, Okoh A. Antibiotic use in agriculture and its consequential resistance in environmental sources: Potential public health implications. Molecules. 2018; 23: 795. DOI: 10.3390/molecules23040795.

30. Todar K. Bacterial Resistance to Antibiotics [document on the Internet]. Available from: http://textbookofbacteriology.net/resantimicrobial_3.html (accessed in July $16^{\text {th }}$ 2021).

31. Martínez JL, Baquero F. Emergence and spread of antibiotic resistance: setting a parameter space. Upsala Journal of Medical Sciences. 2014; 119 (2): 68-77. DOI: 10.3109/03009734.2014.901444.

32. Busha K. Past and Present Perspectives on $\beta$-Lactamases. Antimicrobial Agents and Chemotherapy. 2018; 62 (10): e01076-18. DOI: 10.1128/AAC.01076-18 .

33. Luthra S, Rominski A, Sander P. The Role of antibiotic-target- modifying and antibiotic-modifying enzymes in Mycobacterium abscessus drug resistance. Frontiers in Microbiology. 2018; 9: 2179. DOI: 10.3389/fmicb.2018.02179.

34. Peterson E, Kaur P. Antibiotic resistance mechanisms in bacteria: relationships between resistance determinants of antibiotic producers, environmental bacteria, and clinical pathogens. Frontiers in Microbiology. 2018; 9: 2928. DOI: 10.3389/fmicb.2018.02928.

35. Reygaert WC. An overview of the antimicrobial resistance mechanisms of bacteria. AIMS Microbiology. 2018; 4(3): 482-501. DOI: 10.3934/microbiol.2018.3.482.

36. LiverTox: Clinical and Research Information on Drug-Induced Liver Injury [document on the Internet]. Bethesda (MD): National Institute of Diabetes and Digestive and Kidney Diseases; 2012-. Penicillins ( $2^{\text {nd }}$ Generation). [Updated 2020 Oct 20]. Available from: https://www.ncbi.nlm.nih.gov/books/NBK548033/ (accessed in July $\left.19^{\text {th }} 2021\right)$. 
37. Parrino B, Carbone D, Cirrincione G, Diana P, Cascioferro S. Inhibitors of antibiotic resistance mechanisms: clinical applications and future perspectives. FutureMed. Chem. 2020; 12(5): 357-359. DOI: 10.4155/fmc-2019-0326.

38. Ghai I, Ghai S. Understanding antibiotic resistance via outer membrane permeability. Infection and Drug Resistance. 2018; 11: 523-530.

39. May KL, Grabowicz M. The bacterial outer membrane is an evolving antibiotic barrier. PNAS. 2018; 115 (36): 8852-8854. DOI: 10.1073/pnas.1812779115.

40. Choi U, Lee CR. Distinct roles of outer membrane porins in antibiotic resistance and membrane integrity in Escherichia coli. Frontiers in Microbiology. 2019; 10: 953. DOI: $10.3389 /$ fmicb.2019.00953.

41. Palmer AC, Kishony R. Opposing effects of target overexpression reveal drug mechanisms. Nature Communications. 2014; 5: 4296. DOI: 10.1038/ncomms5296.

42. CDC. Antibiotic resistance threats in the United States. CDC. USA. 2013; 114 pages.

43. Melander RJ, Zurawskib DV, Melander C. Narrow-spectrum antibacterial agents. Med. Chem. Commun. 2018; 9: 12. DOI: 10.1039/c7md00528h.

44. Chen J, Sidibi AM, Shen X, Dao K, Maiga A, et al. Lack of antibiotic knowledge and misuse of antibiotics by medical students in Mali: A cross-sectional study. Expert Review of Anti-infective Therapy. 2021; 19 (6): 797-804. DOI: $10.1080 / 14787210.2021 .1857731$.

\section{BJMHR is}

- Peer reviewed

- Monthly

- Rapid publication

- Submit your next manuscript at editor@bjmhr.com 